2017-08-23

\title{
A serious game enhancing social tenants' behavioral change towards energy efficiency
}

\section{Casals, M}

http://hdl.handle.net/10026.1/13634

\subsection{9/GIOTS.2017.8016257}

GloTS 2017 - Global Internet of Things Summit, Proceedings

All content in PEARL is protected by copyright law. Author manuscripts are made available in accordance with publisher policies. Please cite only the published version using the details provided on the item record or document. In the absence of an open licence (e.g. Creative Commons), permissions for further reuse of content should be sought from the publisher or author. 


\section{A serious game enhancing social tenants' behavioral change towards energy efficiency}

\author{
M. Casals, M. Gangolells, M. Macarulla \\ Group of Construction Research and Innovation, \\ Technical University of Catalonia, \\ Terrassa, Spain \\ miquel.casals@upc.edu \\ V. Vimont \\ Fremen Corp, \\ Troyes, France \\ vincent@fremencorp.com
}

\author{
A. Fuertes \\ Plymouth University, \\ Plymouth, United Kingdom \\ alba.fuertes@plymouth.ac.uk \\ L.M. Pinho \\ Polytechnic Institute of Porto, \\ Porto, Portugal \\ lmp@isep.ipp.pt
}

\begin{abstract}
The energy consumption of the current building stock represents about $40 \%$ of the total final energy consumption in Europe. New gamification techniques may play a significant role in helping users adopt new and more energy efficient behaviours. This paper presents the advances achieved within the context of the EU-funded project EnerGAware - Energy Game for Awareness of energy efficiency in social housing communities. The main objective of the project, funded by the European Union under the Horizon2020 programme, is to reduce the energy consumption and carbon emissions in a sample of European social housing by changing the energy efficiency behaviour of the social tenants through the implementation of a serious game linked to the real energy use of the participants' homes.

Index Terms-Serious game, energy efficiency, behavior change.
\end{abstract}

\section{INTRODUCTION}

The building sector currently accounts for $40 \%$ of energy use in most countries [1,2] and has the greatest energy saving potential [3], with estimated potential energy savings of 1509 million tonnes of oil equivalent (Mtoe) by 2050 [4]. As a consequence, the cornerstone of the European energy policy has an explicit orientation to the conservation and rational use of energy in buildings [5]. As buildings tend to have long lifespans and there is currently low turnover in the sector, new building codes are not expected to have a significant impact on the building stock as a whole in the short- and medium-term [6]. Thus, to maximize the energy saving potential of the building sector, energy efficient initiatives must be focused on the existing building stock.

One of the most cost-effective ways of addressing this challenge is thought to be the promotion of energy users' behavioural change. An emerging area of focus is the use of serious games and gamification as tools to motivate engage and educate people regarding energy consumption and related concerns [7]. Relevant initiatives within this area are Power Explorer [8, 9], Super Energy Apocalypse [10], Energy Life [11], Power House [12], EnerCities [13], Super Delivery [14], Ghost Hunter [15], Personal Energy [16], Do it in the dark [17], eViz [18] and others reviewed by Johnson et al. [7], Fijnheer and van Oostendorp [19] and Ouariachi et al. [20]. After a thorough literature review seeking effectiveness of serious games in impacting domestic energy consumption, Johnson et al. [7] concluded that gamification and serious game appear to be of value within the domain of energy consumption, conservation and efficiency with varying degrees of evidence of positive influence found for behavior, cognitions, knowledge and learning and user experience.

This paper presents the advances achieved within the EUfunded project EnerGAware - Energy Game for Awareness of energy efficiency in social housing communities [21]. The main objective of the project is to contribute to energy consumption and carbon emissions reduction in social housing by increasing the tenants' understanding and engagement in energy efficiency [22]. The project relies on serious gaming to enhance energy users' behavioural change through education and training. The developed game is now deployed in real life conditions in an affordable housing pilot located in Plymouth (United Kingdom). The energy consumption of the social housing pilots, as well as the awareness, attitudes, engagement and self-reported behaviours of the social tenants are being assessed both before and after the implementation of the serious game. Preliminary results show a daily electricity saving ranging from 3 to $10 \%$. Once the project is finished, it will provide more quantitative empirical research on the effectiveness of serious games within the domain of domestic energy reduction, covering the need identified by most authors in the literature (i.e. [7]).

\section{CONCEPT AND APPROACH}

The game has been designed under an iterative process that included (1) the identification and analysis of user, building and game requirements (taking into account the feedback received during a series of gameplay scenarios focus groups), followed by (2) the design and development of the prototype and beta versions of the serious game (considering again the opinion of the play-test prototype feedback focus groups) and (3) the implementation, monitoring and evaluation of the game in a real social housing pilot, where the feedback obtained from the group of social tenants interacting with the game is also taken into account. 


\section{A. Identification of user, building and game requirements}

As detailed in Casals et al. [22], requirements were defined using a range of different datasets and methods including (1) literature review; (2) a large-scale, city-wide survey, undertaken in Plymouth (United Kingdom), during 2015, which was administered to all the 2,772 social houses managed by the social housing provider partaking in the EnerGAware project; (3) three game-play scenarios focus groups undertaken with social housing tenants in Plymouth, during 2015 and (4) a social housing building stock database gathered and managed by project partner DCH (Building Stock Condition Database).

Analysis of specific user requirements [23] allowed concluding that the EnerGAware serious game virtual world should be based on a domestic environment. Requirements derived from human aging process and novice users were also deemed to be important. The game should easily accommodate different learning levels and provide clear and easy to understand goals. Communication and information sharing amongst players was also found to be relevant.

Analysis of specific building requirements [24] allowed concluding that the design of the virtual home should be influenced by a 'typical' social dwelling in terms of building characteristics, envelope, services, controls and renewable energy generation. Information about the energy metering and monitoring systems existing in social homes internet availability and coverage was also analysed to design the energy metering and data communication infrastructure.

Analysis of specific game requirements [25] allowed concluding that the online serious game approach adopted for the EnerGAware serious game should not be a barrier for the targeted audience. Focus groups concluded that a pseudorealistic game setting would be better than a fantasy world (or sci-fi, or cartoon) and better than a fully-realistic simulation. A tactile tablet was found to be the most suitable IT device (both technically and cost-effectively) for the deployment of the EnerGAware serious game.

\section{B. Game development}

The game has been developed using the Living Lab methodology and the spiral user-centred approach. Therefore, tenants have been brought together to co-create the serious game and have had an active part in the process of research, development and innovation. In the context of the EnerGAware serious game design, the Living Lab has been based on the social housing community (the pilot). At the beginning, the Living Lab consisted of a series of focus groups aimed at, firstly, collecting the social tenants' ideas and inputs in relation to the initial game concepts, and later, testing early game prototype ideas and developments. Afterwards, the Living Lab became the pilots for the deployment and testing of the EnerGAware serious game integrated with the energy metering system.

The beta version of the game was launched in January 2017 for Android tablets. The game is called Energy Cat: the House of Tomorrow (http://energycatgame.com) and a short gameplay teaser is available in the EnerGAware Youtube channel (https://www.youtube.com/watch? $\mathrm{v}=\mathrm{jdhJ} 0 \mathrm{~S} 1 \mathrm{CVG}$ ) $)$.
In the game, users take the role of the Energy Cat, a cat who dreams about living in a house both comfortable and energy efficient (Fig. 1). To attain this objective, the Energy Cat has to keep an eye on the behaviour of his humans and correct multiple energy non-sense while ensuring their wellbeing. Energy savings achieved in the virtual house, calculated by building performance simulation, provide rewards. The player can customize his house through an equipment and furniture shop (Fig. 2). Users have also the opportunity to extend the house layout and add a second floor.

The main gameplay loop starts with a daily pool of energy points. The Energy Cat has an operational house with certain global energy consumption and needs to save energy points.

Energy points allow the Energy Cat unlocking new game items and/or upgrades that might be more efficient (e.g. a more energy efficient fridge) or smarter (e.g. a bigger TV). The Energy Cat needs to decide whether to invest in low cost options providing low energy savings (i.e. replacing incandescent bulbs by CFL bulbs or LED bulbs, etc.), or high cost options providing high energy savings (i.e. solid wall insulation, solar photovoltaic panels, etc.). The Energy Cat also needs to correct human actions that are wasting energy (reduction of heating and cooling temperatures or durations; turn off appliances in standby mode, etc.). In general, energy efficient items and actions increase the global happiness and thus, the daily money income. Money can be then used to buy other new items. Reducing the happiness level too much to save energy points decrease humans' productivity and as a consequence, they earn less money.

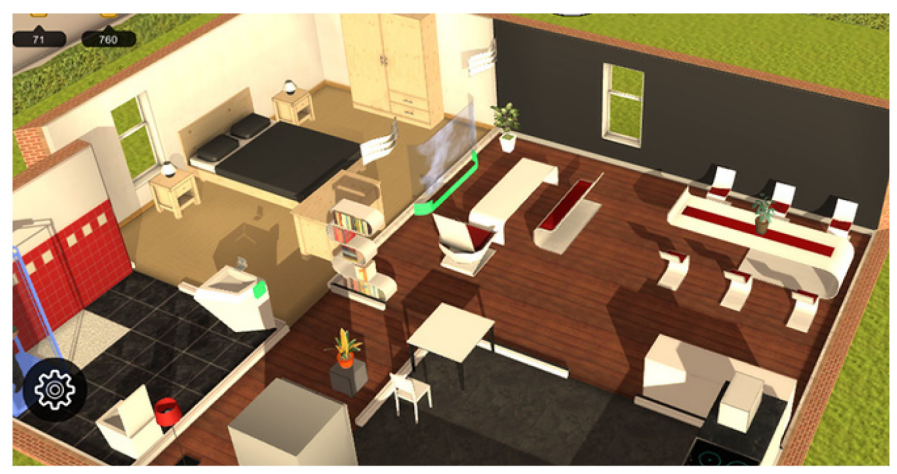

Fig. 1. Main house in the game Energy Cat: the House of Tomorrow.

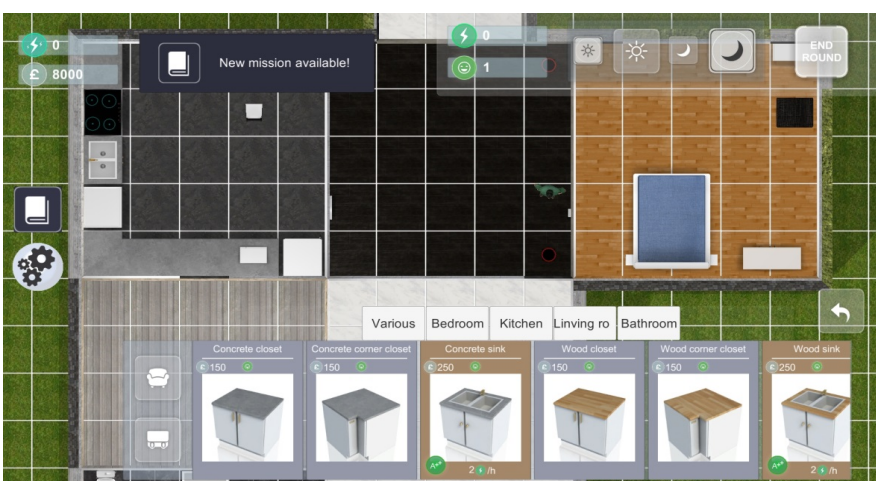

Fig. 2. Shop in the game Energy Cat: the House of Tomorrow. 
Story missions gradually happen in the game and they help to learn how to play with the game but also energy efficient habits by asking to do simple actions. Event missions are available only during specific periods. These missions focus on real events such as Christmas or the World Environment Day.

When progressing with the game, new features are unlock such as the possibility of visiting neighbour's houses through the street view (Fig. 3) and interacting with them. Some of the neighbours are strong adept of smart energy consumption while others need to be trained. The Brightest family is the worst at saving energy. The Energy Cat needs to change their behaviour until they save energy. The Aye O'Tea family use technology in everything they can. The problem is they often forget to turn off appliances or to unplug them. The Energy Cat needs to try to raise their awareness about the importance of saving energy by giving advice and taking care of the appliances used. Mrs Young is an old woman with a young spirit. However, she does not really like technical novelties. Finally, the Green family lives in a very efficient house and the Energy Cat will discover lots of tips to save energy.

Thanks to the energy monitoring and communication infrastructure installed in users' homes, the game displays how many real energy the user spent last week compared to the previous one. The data is weighted according to the climate severity. Players making real energy savings receive rewards in the game.

Social media features provide players a platform to share data of their achievements, compete with each other, give energy advice, as well as, join together to form virtual energy communities.

\section{Implementation, monitoring and evaluation of the game}

The project aims to assess the contribution of the game to change energy consumption behaviour and habits towards a more efficient energy use. This analysis requires the collection of data to determine how energy use has evolved over time, and how this is related to the experience of the game.

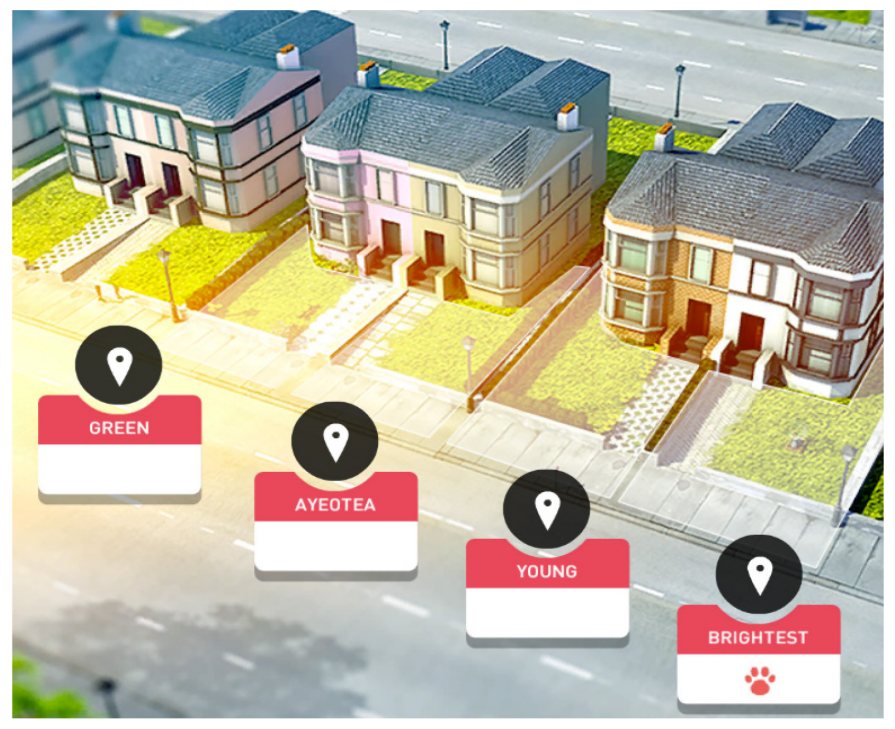

Fig. 3. Neighbour's houses in the game Energy Cat: the House of Tomorrow.
Electricity and gas consumption are automatically monitored with a 15 minutes period, by reading the actual electricity and gas home meters of the pilot homes. For the electricity, an optical pulse reader and an standard wireless Mbus pulse counter are attached to the pre-existing meters. This set allows sending information wirelessly from the meter (usually located outdoor) to the data concentrator. For the gas, energy cams read data from the existing meters and transform it into an M-Bus parameter to be read wirelessly by the data concentrator. The data concentrator collects data from the aforementioned sensors and sends it to the remote server through a GPRS connection.

Considering that the energy consumption is related to the weather conditions, daily weather parameters, especially air temperature, are also retrieved from a local weather platform.

The game experience for each home is determined by the overall time that the home residents have played the game and the progress that they have achieved throughout the game (earned points).

The EnerGAware middleware (Fig. 4) aggregates all this data (energy consumption, weather and game experience) and exports the same data in a suitable format for a post analysis. The game incorporates a system of player rewards determined by energy savings in the real, physical world, such that these rewards can be used by the player to improve his progress in the game. The EnerGAware middleware must compute these real-world energy savings and provide this data to the game server.

Finally, data such as overall energy consumption and achieved reduction may be displayed to the general public, after being anonymised and aggregated, such that individual homes cannot be discerned nor identified.

The life-simulation game has been deployed and is being validated in real life conditions in an affordable housing pilot located in Plymouth (United Kingdom).

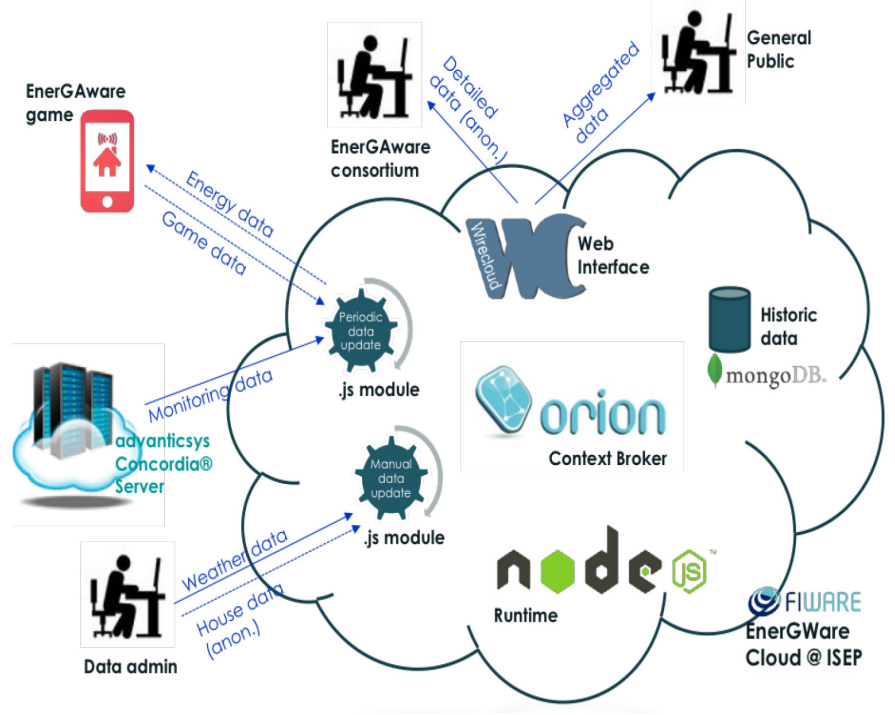

Fig. 4. EnerGAware middleware. 
In accordance to the International Performance Measurement and Verification Protocol (IPMVP) [26] and within the pre-post comparison approach, the effect of the serious game is being estimated in more than 40 households playing the game since January 2017 by evaluating their energy consumption, electricity peak demand and other indicators (related to self-reported energy consumption behaviours and awareness, energy knowledge, social media activity, ITliteracy, etc.) before (baseline evaluation), after the intervention starts (mid-term evaluation) and at the end of the intervention (final evaluation).

In addition and following the recommendation in the European ICT PSP Methodology for energy savings measurement [27], a control group approach has also been implemented. The control group is composed by near 40 households not playing with the game but being monitored in terms of energy consumption. In this way, data are collected over the same time period for both the experimental and control group and therefore external influences (e.g. energy price changes, longer school holidays, sports events, etc.) which could have an effect on the measured dependent variables are also considered. The game includes tracking analytics so they can be used during the validation of the project.

Earliest results in five randomly chosen houses show that the Energy Cat: the House of Tomorrow serious game seems to successfully change the short-term energy efficiency behaviour of the tenants (Fig. 5). Table 1 reports the tenants' game activity. Energy savings have been calculated for the reporting period (after the implementation of the game) in relation to the baseline period (before the implementation of the game). For a a given house, the baseline and the reporting period have the same duration for and range between 15 and 36 days. Taking into account the impact of the weather (namely, heating degree days based at $15.5^{\circ} \mathrm{C}$ ), the electricity saving of the five houses during the reporting period was found to range from $3 \%$ and $10 \%$, approximately (Fig. 5). Both the maximum and the minimum daily electricity consumption have decreased during the reporting period in relation to the baseline period in all the houses. In general, those tenants achieving higher scores and completing a higher number of missions in the game achieve higher electricity savings. However and in order to ratify these initial findings, the analysis should be extended to cover all the houses in the pilot within the pre-post comparison approach.
TABLE I. GAME ACTIVITY

\begin{tabular}{|c|c|c|}
\hline House & Score achieved & $\begin{array}{c}\text { Number of } \\
\text { completed missions }\end{array}$ \\
\hline House E1 & 595 & 54 \\
\hline House E2 & 54 & 25 \\
\hline House E3 & 162 & 29 \\
\hline House E4 & 50 & 22 \\
\hline House E5 & 43 & 19 \\
\hline
\end{tabular}

Along this line, evaluation periods should be extended so as to assess not only the short-term but also the mid-term and the long-term impact of the game, as there is a recognised need to explore the effectiveness of applied games over a long timeframe [7]. The energy performance of the houses in the experimental group was compared with that of houses in the control group. As shown in Figure 5, results were found to be significantly better in the experimental group.

In addition, an initial assessment of the business and environmental cost-benefit opportunity associated with the EnerGAware serious game allows concluding that the energy savings achieved through this ICT-enabled solution are greater than the cost for the provision of the services. Therefore, preliminary validation provides socio-economic evidence for ICT investment in the field and allows envisaging future largescale uptake beyond the project's life time. The serious game could be distributed to energy customers by energy providers in the form of a free to download tablet or smart phone application, as part of the European smart meter roll-out

\section{CONCLUSIONS}

The EnerGAware project (Energy Game for Awareness of energy efficiency in social housing communities) is an excellent and innovative example of rewarding actions leading to the behavioural change of individual energy users. Initial findings in the short-term have been found to be promising in terms of energy saving. However and in order to confirm these preliminary results, the analysis should cover all the houses in the experimental group. In addition, the baseline and the reporting periods should be extended to be able to assess both the mid-term and the long-term impact of this intervention.

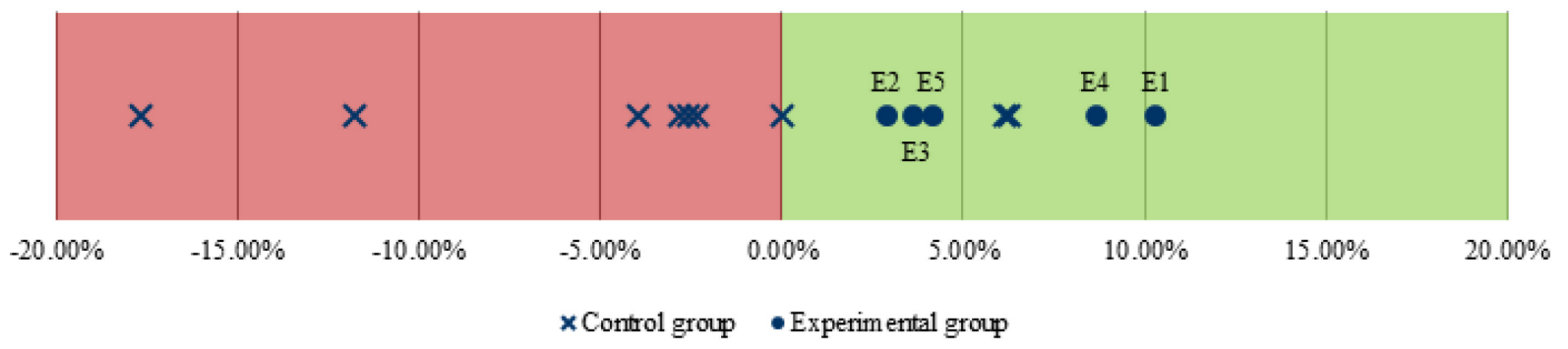

Fig. 5. Electricity savings achieved during the reporting period in relation to the baseline period for houses of both the experimental and the control groups. 
Obtained results must take into account that in this case, tenants play the game voluntarily in contrast with other serious games for corporate training where employees are forced to play. Taking into account this voluntarily approach, the game was designed to be highly engaging and fun with a very attractive visual aspect. However, not all the tenants play enough time so as to take advantage of all the game features. Therefore and in order to promote the intended effect of the game, tenants should be encouraged to keep playing more time. This is important as tenants do no appreciate the real advantage of saving energy until a month later when the energy bill is out.

The project has made significant advances beyond the current state-of-the-art, in a range of different areas including, reducing energy consumption in social housing, serious gaming, cloud computing and energy monitoring, behaviour change psychology, and social media and networking [22]. Although the validation stage of the project has not been finished yet, preliminary results predict a high impact, social acceptance and replication potential.

This project will clearly benefit citizens as it will provide greater understanding and engagement in energy efficiency. Thanks to the game, users will learn how to reduce the energy wasted in their home. Consequently, the game will enable a reduction in fuel percentage of household income spent on energy bills. In addition and in some cases, the project will provide increased IT-literacy, empowerment and e-inclusion.

Results obtained in this project are found to be highly transferable across the EU. In light of the successful results, other stakeholders such as social housing providers, public authorities, energy service providers, ICT industry, etc. may be encouraged to adopt a similar approach so as to increase people understanding and awareness of the options for reducing energy consumption in residential buildings.

Social housing agencies may also be interested in adopting the advances provided by the EnerGAware project. Taking into account that refurbishment actions in social housing must be financed by the public administration, the EnerGAware project provides a unique opportunity of decreasing the energy consumption of the housing stock with limited economic resources. The serious game may also help in promoting energy efficiency in private housing and therefore private housing agencies are also seen as potential beneficiaries of the project.

Changing the users' energy efficiency behaviour will result in a reduction of the domestic energy consumption and corresponding emissions. Taking into account that new gamification techniques may play a significant role in motivating and supporting citizen's behavioural change, energy agencies and other European Union, national or regional public authorities will also benefit of the development of the Energy Cat: the House of Tomorrow.

Energy service providers are also potential beneficiaries of the game as they can use it as a customer engagement tool with opportunities to place advices, services or physical products to generate additional revenue streams. By using a gamified interface to engage with customers, an energy supplier would be able to communicate with his customers in a user friendly, unique, and appealing way that differentiates against the competition encouraging customer loyalty. This may contribute to distinguish its marketing offer allowing the retention of existing customers, the acquisition of new customers and generally improving customer relationships. In this sense, it is important to highlight that the European smart meter roll-out will significantly ease the provision of real users' homes energy consumption feedback.

Finally, ICT industry and game developers may also benefit from this initiative as the achieved results may encourage them to invest in the sector and encourage further deployment of ICT solutions for energy efficiency integrating energy consumption data from smart meters. Taking into account that the game is a cleanweb solution, this project sets the basis of a very promising investment field that capitalizes the potential of IT and network-based technologies to develop solutions that reduce the environmental burden.

\section{ACKNOWLEDGMENT}

This project has received funding from the European Union's Horizon 2020 research and innovation programme under grant agreement No 649673. The project is being carried out jointly by the Universitat Politecnica de Catalunya (Spain), the University of Plymouth (United Kingdom), the Instituto Superior de Engenharia do Porto (Portugal), Fremen Corp (France), Advantic Sistemas y Servicios (Spain), DCH Devon and Cornwall Housing (United Kingdom) and EDF Energy R\&D UK Centre Limited (United Kingdom).

\section{REFERENCES}

[1] European Union, "Directive 2012/27/EU of the European Parliament and of the Council of 25 October 2012 on energy efficiency, amending Directives 2009/125/EC and 2010/30/EU and repealing Directives 2004/8/EC and 2006/32/EC", 2012. Available at: http://eur-lex.europa.eu/legalcontent/EN/TXT/?uri=celex\%3A32012L0027 (accessed 22.02.17).

[2] European Union, "EU Energy in figures. Statistical pocketbook 2016," 2016. Available at: https://bookshop.europa.eu/en/euenergy-in-figures-pbMJAB16001/ (accessed 22.02.17).

[3] European Commission, "Communication from the Commission to the European Parliament, the Council, the European Economic and Social Committee and the Committee of the Regions. Energy efficiency plan 2011”, 2011. Available at: http://eur-lex.europa.eu/legalcontent/EN/TXT/?uri=URISERV\%3Aen0029 (accessed 22.02.17).

[4] International Energy Agency, "Energy performance certification of buildings. A policy tool to improve energy efficiency," 2010. Available at: http://www.iea.org/publications/freepublications/publication/bui ldings certification.pdf (accessed 22.02.17).

[5] E. Asadi, M. Gameiro da Silva, C. Henggeler Antunes, and L. Dias, "Multi-objective optimization for building retrofit strategies: A model and an application," Energy and Buildings, vol. 44, pp. 81-87, 2012.

[6] M. Gangolells, M. Casals, N. Forcada, M. Macarulla and E. Cuerva, "Energy mapping of existing building stock in Spain," Journal of Cleaner Production, vol. 112, pp. 3895-3904, 2016. 
[7] D. Johnson, E. Horton, R. Mulcahy, M. Foth, "Gamification and serious games within the domain of domestic energy consumption: A systematic review", Renewable and Sustainable Energy Reviews, vol. 73, pp. 249-264, 2017.

[8] A. Gustafsson, "Power explorer: a casual game style for encouraging long-term behavior change among teenagers", Proceedings of the International Conference on Advances in Computer Enterntainment Technology, p. 182-189, 2009a.

[9] A. Gustafsson, C. Katzeff, and M. Bang, "Evaluation of a pervasive game for domestic energy engagement among teenagers", Computers in Entertainment (CIE), vol. 7(4):54:154(19), 2009b.

[10] L. Doucet, and V. Srinivasan, "Designing entertaining educational games using procedural rhetoric: a case study", Proceeding of the 5th ACM SIGGRAPH Symposium on Video Games, p. 5-10, 2010.

[11] L. Gamberini, N. Corradi, L. Zamboni, et al., "Saving is fun: designing a persuasive game for power conservation", Proceedings of 8th International Conference on Advances in Computer Entertainment Technology, p. 1-7, 2011.

[12] B. Reeves, J. J. Cummings, D. Anderson, "Leveraging the engagement of games to change energy behavior", CHI May 2011. ACM Press, Vancouver, BC, 2011.

[13] E. Knol, P.W. De Vries. "EnerCities - A serious game to stimulate sustainability and energy conservation: Preliminary results", eLearning Papers, vol. 25, pp.1-10, 2011.

[14] F. H. Tsai, K. C. Yu, H. S. Hsiao, "Exploring the factors influencing learning effectiveness in digital game-based learning", Educational Technology \& Society, vol. 15, pp. 24050, 2012.

[15] A. Banerjee, M. S. Horn. "Ghost hunter: Parents and children playing together to learn about energy consumption", Proceedings of the 8th International Conference on Tangible, Embedded and Embodied Interaction, TEI'14, pp. 267-274; 2014.

[16] P. Salas-Prat, S. Zelco, J. Carrasco, R. Segura, "Sociological analysis, social networks and gamification to change the energy consumption in households", Proceedings of Behave Energy Conference 2014, BEHAVE2014, 2014.

[17] M. Senbel, V. D. Ngo, E. Blair., "Social mobilization of climate change: university students conserving energy through multiple pathways for peer engagement", Journal of Environmental Psychology, vol. 38, pp. 84-93, 2014.
[18] R. Stone, R. Guest, S. Pahl, C. Boomsma, "Exploiting gaming technologies to visualise dynamic thermal qualities of a domestic dwelling: Pilot study of an interactive virtual apartment", Behave Energy Conference 2014, BEHAVE2014; 2014.

[19] T. Ouariachi, M. D. Olvera-Lobo, J. Gutiérrez-Pérez, “Gaming Climate Change: Assessing Online Climate Change Games Targeting Youth Produced in Spanish" Procedia - Social and Behavioral Sciences, vol. 237, pp. 1053-1060, 2017.

[20] J. D. Fijnheer, H. van Oostendorp, "Steps to Design a Household Energy Game", Games and Learning Alliance conference 2015, LNCS 9599, pp. 12-22, 2016.

[21] EnerGAware project, "Energy Game for Awareness of energy efficiency in social housing communities," EU funded project, contract number: 649673, 2016. Available at: http://energaware.eu/ (accessed 22.02.17).

[22] M. Casals, M. Gangolells, M. Macarulla, A. Fuertes, R. Jones, S. Pahl, and M. Ruiz, "Promoting energy users' behavioural change in social housing through a serious game," European Conference on Product and Process Modelling, p. 573-577, 2016.

[23] EnerGAware project, "D2.1. User requirements," 2016. Available at: http://www.energaware.eu/downloads/EnerGAware D2.1 User \%20Requirements_r1.pdf (accessed 23.02.17).

[24] EnerGAware project, "D2.2. Building requirements," 2016. Available

at: http://www.energaware.eu/downloads/EnerGAware_D2.2_Build ing_Requirements\%20 r1.pdf (accessed 23.02.17).

[25] EnerGAware project, "D2.3. Game requirements," 2016. Available http://www.energaware.eu/downloads/EnerGAware_D2.3_Gam e Requirements_r1.pdf (accessed 23.02.17).

[26] EVO Efficiency Valuation Organisation, "International performance measurement and verification protocol. Concepts and options for determining energy and water savings," vol. 1, Technical Report, 2012. Available at: http://www.nrel.gov/docs/fy02osti/31505.pdf Iaccessed 25.02.17).

[27] BECA Balanced European Conservation Approach, "The ICT PSP Methodology for Energy Saving Measurement: A common deliverable from projects of ICT for sustainable growth in the residential sector," 2012, version 3 . 